\title{
Types of Student Errors in Mathematical Symbols, Graphs and Problem-Solving
}

\author{
Arsaythamby Veloo ${ }^{1}$, Hariharan N. Krishnasamy ${ }^{1} \&$ Wan Shahida Wan Abdullah ${ }^{2}$ \\ ${ }^{1}$ School of Education and Modern Languages, Universiti Utara Malaysia (UUM), Malaysia \\ ${ }^{2}$ SMK Tengku Mahmud 2, Besut, Terengganu, Malaysia \\ Correspondence: Arsaythamby Veloo, School of Education and Modern Languages, University Utara Malaysia, \\ 06010 Sintok, Kedah, Malaysia. E-mail: arsay@uum.edu.my
}

\author{
Received: February 17, 2015 Accepted: March 11, 2015 Online Published: May 15, 2015 \\ doi:10.5539/ass.v11n15p324 URL: http://dx.doi.org/10.5539/ass.v11n15p324
}

\begin{abstract}
This study aims to identify the level of difficulty, discrimination and errors based on symbols, graphs and problem-solving in mathematics achievement. The participants consisted of 315 grade 10 students randomly selected from eight secondary day schools situated in the state of Kedah, Malaysia. The mathematics written test consisted of 15 open-ended items with five items each for symbols, graphs and problem-solving and all the items were analyzed using the difficulty and discrimination index. Semi-structured clinical interviews were also carried out among 20 selected students to identify the errors they had made in mathematics. In the content analysis, the descriptor code key was used to identify conceptual, careless, problem- solving and value errors. The findings showed that item 4 (Standard Form) of the symbols, item 6 (Linear Equation) of the graphs, and item 15 (Line \& Plane in 3 Dimension) of the problem-solving was the most difficult item in mathematics. All of these items had a good discrimination as well as difficulty index. Content analysis showed that $52(57 \%)$ students made conceptual errors, 22 (24\%) made careless errors, 12 (13\%) made problem-solving errors and 5 $(6 \%)$ made value errors. The major reasons given for errors made were a lack of understanding, procedures being forgotten, negligence in transcribing information from the question, carelessness and guesswork. This study has implications for the student learning process and understanding graphs because graphs are widely used in daily life to manage, communicate and analyze information.
\end{abstract}

Keywords: symbol, graph, problem-solving, errors, mathematics achievement.

\section{Introduction}

Competency in mathematics is the key towards the goal of establishing a scientific and technologically orientated society. It is also important to produce a generation that is competent in the field of science and technology to continually progress in the era of globalization. Mathematical skills enable students to delve into various fields such as economics, engineering, business, computer science and technology. Mathematics tests the students' intelligence to think and solve daily life problems. The ability to remember concepts, memorize facts, manipulate numbers and solve mental puzzles is driven by the memory power of mathematics. Kailani and Natasha (2011) state that mathematics provides basic computational skills and relevant knowledge that helps to solve mathematical problems.

The problem of understanding mathematics is experienced by almost all the countries in the world. The National Research Council (NRC) Report in the United States revealed that U.S. students underperform in mathematics. Meanwhile, U. S. students also demonstrated limited abilities in understanding mathematical concepts and cannot apply knowledge to solve new mathematical problems (van Es Elizabeth \& Conroy, 2009). The report in Trends in International Mathematics and Science Study (TIMSS) shows that the achievement levels in Mathematics in Malaysia has declined from 1999 to 2011 compared with Singapore which occupies the first place (Mullis, Martin, Foy, \& Arora, 2012). The Education Development Plan of 2001 to 2010 shows that the "Ministry of Education (MOE) faces the challenge of increasing the percentage of enrolment in the science stream which is still below the target of 60:40 for the science and technology stream compared with literature" (MOE, 2001, p. 4). This is because most students make mistakes in understanding mathematical concepts during the early stages of learning, and this affects their ability in mathematics at a higher level. 
Failure in the early stages of conceptual understanding of mathematics learning poses difficulty in understanding at the secondary school level and at institutions of higher learning. Therefore, it is very important for the children to grasp the correct basic mathematics concepts at the early stages of their learning process. Furthermore, the successful application of rules to symbols in any mathematics problem can be considered a failure if the students are not able to interpret the result of their efforts. So, one of the ways to monitor what children understand is to observe them solve the problems and ask them to explain what they do when they solve it. Students who memorized the 'magical procedures' in fact could produce brilliant answers but could not reason out simple problems or sometimes gave contradictory answers (Suhaidah, 2006). Mathematical concepts are taught using quantitative methods using graphs, numerical scales and applications. Students' lack of numerical skills can affect mathematics achievement (Schuhmann, McGoldrick, \& Burrus, 2005). Similar to challenges in many parts of the world that emphasize the importance of mathematics education and its challenges, Malaysia too is grappling with issues related to errors in mathematical symbols, graphs and problem-solving.

\subsection{Types of Errors in Mathematics}

Several studies have shown that students as well as teachers have problems understanding numbers such as misconceptions about numbers or discriminating numbers. A study by Giannakoulias, Souyoul and Zachariades (2007) and Sirotic and Zazkis (2006) showed that first semester undergraduates who majored in Mathematics had problems to understand whole numbers even though they had done calculus during upper secondary school. Similarly, an earlier study by Fischben, Jehiam and Cohen (1995) showed that students as well as teachers were not able to make a distinction between different types of numbers at the high school level. A study of 46 teachers in a secondary school on mathematical understanding of numbers showed that most teachers had misconceptions and consequently had problems applying numerical knowledge for solving mathematical problems that required more complex operations (Sirotic \& Zazkis, 2006).

Ben-Chaim, Chang and Greenes (2005) found that many students have problems distinguishing the slope of the line graph and the relationship between the slope based on the graph. Among the errors committed by the students is that they cannot distinguish when the value of $\mathrm{x}$ should replace a negative value and when the value of $x$ should be used as a positive value. In addition, students do not pay attention to the relationship between the direction of a line and the label of the slope, but are only concerned with changes in the value of $\mathrm{x}$ and $\mathrm{y}$.

Tuba-Ada and Aytac-Kartulus (2010) conducted a study to identify Turkish students' misconception and errors in transformation geometry. The findings showed that students' performance were lower on conceptual items than procedural items for rotation and translation. These findings also highlight that students knew the algebraic meaning of translation and rotation but they did not understand the concepts in transformation geometry. McNamara and Shaughnessy (2011) posit that interpreting error as a careless mistake usually leads teachers to assume that the students would provide the correct answer if the question is given to them on another day. Ruzlan, Rosalinda and Arsaythamby (2013) in their study on error analysis showed the lack of conceptual understanding of fractions among remote lower secondary school students in Sabah, Malaysia. Among the reasons given for errors made was confusion, insufficient time, anxiety, forgetting the procedures, carelessness, and difficulty of questions. Sharmiza (2010) was able to identify comprehension errors of students when they made cumulative frequency tables and drew ogive.

In a study of grade ten students, Chang (2010) identified nine types of errors related to the slope of a line, namely, incomplete or no response, wrong value substitution, graph value, calculation, not following instructions given/misinterpreting the requirement of the question, gradient identification, addition of negative values indiscriminately, unacceptable form, and others. In another study related to mathematical errors, Noor Safiyah's (2009) examined the types of errors made by students in solving straight line equations. The respondents were 40 grade 10 students from the state of Perak, Malaysia. The results showed that students committed various types of errors in solving straight line equations. Among the types of errors that were identified by researchers include erroneous application of the formula $\mathrm{y}=\mathrm{mc}+\mathrm{c}$, careless mistakes, and errors when solving linear equations. Errors in the application of the formula $\mathrm{y}=\mathrm{mx}+\mathrm{c}$ recorded the highest percentage at $46 \%$, while careless mistakes recorded the second highest at $31 \%$. The lowest percentage of errors was for solving straight line equations. Based on findings from previous studies, we can infer that there are four types of errors, that is, errors of concept, value, problem-solving and carelessness.

The purpose of this study is to identify the level of difficulty and discrimination of symbols, graphs and problem-solving as indicators of secondary school students' achievement in Mathematics. The study also explores the type of mistakes made by the students taking mathematics in relation to symbols, graphs and problem-solving. 


\section{Methodology}

This study used quantitative and qualitative methods involving mathematics test, content analysis and interviews. A total of 315 students were chosen from eight districts and each district represents a school. A total of 40 grade 10 students were selected from each daily national secondary school in the state of Kedah. The written test consisted of 15 open-ended items with five items each for symbols, graphs and mathematical problem-solving. Symbols, graphs and problem-solving are independent variables and mathematics achievement is the dependent variable. Symbols, graphs and problem-solving were selected based on a critical component of the Malaysian mathematics curriculum. The 15 open-ended items were chosen from the Malaysia Certificate of Education nation-wide public examination (grade 11). Data were analyzed using the difficulty and discrimination index. Semi-structured interviews were also carried out among 20 selected students to identify the errors they had made in the process of solving mathematics. In content analysis, the descriptor code key was used to identify the four types of errors, that is, conceptual, careless, problem-solving and value error. These categories were derived from the most frequently occurring errors based on the literature review. The data was then analyzed and issues that emerged were probed through a semi-structured clinical interview with selected subjects.

To determine the level of item difficulty for symbols, graphs and problem-solving, the item difficulty index is used. The difficulty index and discrimination index are necessary to measure students' performance (Sabri, 2013) and types of errors. Items that have a difficulty index below 0.30 are classified as having a high level of difficulty and those above 0.70 is considered to be low-level. Items that have difficulty index between the two values above $(0.30-0.70)$ are considered to have a moderate level of difficulty (Kaplan \& Saccuzzo, 2001). Additionally, the discrimination index is used to determine the student response. For an ideal test, the point-biserial index is between 0.3 - 0.6 (Bond \& Fox, 2001).

\subsection{Content Analysis and Student Interview Responses}

The content analysis was conducted on students' answer sheets obtained from the grade ten mathematics tests. Analysis was conducted to identify the types of errors made by the students. In the content analysis, the descriptor code key was used to identify the four types of errors, that is, conceptual, careless, problem- solving and value errors. Table 1 shows the symbol of the four types of errors identified under title of symbol, graph and mathematics problem-solving (refer to Appendix A, B \& C.). Semi-structured interviews were also carried out among 20 selected students to identify the errors they had made in the process of solving mathematics based on symbols, graphs and problem-solving.

Table 1. The key code for types of errors

\begin{tabular}{lll}
\hline Code & Symbols & Type of Error \\
\hline 1 & 0 & Conceptual error \\
\hline 2 & $\triangle$ & Value error \\
\hline 3 & $\square$ & Problem-solving error \\
\hline 4 & $\triangle$ & Careless error \\
\hline
\end{tabular}

This formula below specifically measures the difficulty index of the items.

$$
\text { Difficulty Index } \quad(p)=\frac{\Sigma f X-n(X \min )}{n(X \max -X \min )}
$$

$\Sigma \mathrm{fX}=$ the sum of the frequency multiplied by the score

$\mathrm{n}=$ total number of students

$\mathrm{X} \max =$ maximum score

$\mathrm{X} \min =$ minimum score

The formula for the item-discrimination index is D where: Up and Lp indicate the number of test takers in the upper and lower groups respectively who pass the item, and $U$ is the total number of test-takers in the upper group and $\mathrm{L}$ is the total number of test-takers in the lower group. This formula below specifically measures the Discrimination Index (D) of the items:

$$
\begin{gathered}
\text { Discrimination Index }(D) \quad=\text { Upper Group }(U p)-\text { Lower Group }(L p) \\
\text { Upper Group }=\frac{\frac{\Sigma f X-n(X \text { min })}{n(X \max -X \min )}}{}
\end{gathered}
$$




$$
\text { Lower Group }=\frac{\Sigma f X-n(X \min )}{n(X \max -X \min )}
$$

\section{Findings}

3.1 Identify the Level of Difficulty and Discrimination of Symbols, Graphs and Problem-Solving as Indictors of Secondary School Students' Achievement in Mathematics

The findings showed that the highest achievement is for symbols $(M=3: 39, \mathrm{SD}=1.65)$ based on a maximum score of 5. This gives the impression that the students can understand mathematics by using symbols when compared to graphs and problem-solving. Students who have difficulty in solving the graph only have a mean $(\mathrm{M}=2.14, \mathrm{SD}=1.63)$ compared with the maximum score of 5 . In this study, mathematics consists of three topics which are symbols, graphs and problem-solving and the mathematics achievement on the whole is of a moderate level at $53.78 \%$ (Table 2 ). The reliability of the mathematics test is 0.82 . The reliability for symbols, graphs and problem-solving is $0.86,0.74$ and 0.78 respectively.

Table 2. Student results with symbols, graphs, problem-solving and mathematic achievement

\begin{tabular}{cccc}
\hline Achievement & $\mathrm{N}$ & Mean & Standard Deviation \\
\hline Symbol & 315 & 3.39 & 1.65 \\
Graph & 315 & 2.14 & 1.63 \\
Problem-solving & 315 & 2.53 & 1.55 \\
Mathematics & 315 & 53.78 & 6.62 \\
\hline
\end{tabular}

\subsection{Symbols in Mathematics Achievement}

The symbol test consists of five objective items, namely decimal items, fractions and standard forms as found in the grade ten syllabus. Of the five items, item four (standard forms) was the most difficult item which only $55 \%$ of students were able to answer correctly compared with $45 \%$ of the students who were unable to answer the item. This item also has a high level of discrimination compared with the other items (Table 3).

Table 3. Item difficulty and discrimination for Symbols in mathematics

\begin{tabular}{lccccc}
\hline Item & 1 & 2 & 3 & $\mathbf{4}$ & 5 \\
\hline Difficulty index & 0.72 & 0.75 & 0.75 & $\mathbf{0 . 5 5}$ & 0.62 \\
Discrimination index & 0.31 & 0.33 & 0.43 & $\mathbf{0 . 6 1}$ & 0.60 \\
\hline
\end{tabular}

\subsection{Mistakes Made by the Students Using Mathematics Symbols}

Figure 1 (Appendix A) shows the respondents' achievement in mastering the concept of the standard form is low. Respondents did not understand or forgot the concept of the standard form which requires the number to have a sa, followed by the decimal point and 10X . Among these are PBTL2, PBTP1, PBTP2, PBTP4, PBRL5 and PBRP1. The interviews concur with the analysis of documents.

'... forget ... must have point from the first number on the left' (PBRL5T2)

'... the point must be before the last number of the numbers $x 10$ ' (PBTP2T6)

'... move to the left point to the power of negative' (PBTP1T6)

Moreover, five students (PBTL3, PBTP3, PBRL1, PBRL3, and PBRP4) made conceptual mistakes in the conversion of the basic units from $\mathrm{km}^{2}$ to $\mathrm{m}^{2}$.

Carelessness also contributed to the errors. Students forgot to convert individual numbers to the standard form.

'... forget lah (emphasizer in Malay) want to change the standard form' (PBTP5T4)

'one cannot change the standard form' (PBTL1T3)

'...did not read the question which requires to change your answer to the standard form. Oops... I did not change the standard form' (PBRL4T5)

Students were also negligent when transcribing information from the question.

'... one look at the question, so 3.5 ... become 3.4 ' (PBRP1T1)

'... write the answer from the calculator' (PBTL2)

One student (PBRP5) experienced a problem-solving error in assuming that 104 could be factored. 


\subsection{Graph Achievement in Mathematics}

Graph tests consisted of five objective items and these items were in accordance with the Form Four syllabus. Of the five items, items 6 and 10 were the most difficult items and only $29 \%$ of students answered correctly compared with $71 \%$ of the students who were not able to answer these items. On the other hand, for item 10 , only $33 \%$ of students managed to answer correctly compared with $67 \%$ of the students who were not able to answer the item. Both of these items also have a low discrimination value of 0.33 and 0.38 for the items 6 and 10 respectively (Table 4).

Table 4. Difficulty and discrimination of items graphs in mathematics

\begin{tabular}{lccccc}
\hline Item & $\mathbf{6}$ & 7 & 8 & 9 & 10 \\
\hline Difficulty index & $\mathbf{0 . 2 9}$ & 0.50 & 0.50 & 0.52 & 0.34 \\
Discrimination index & $\mathbf{0 . 3 8}$ & 0.46 & 0.50 & 0.49 & 0.33 \\
\hline
\end{tabular}

Item 6 (linear equation- difficulty index is 0.29 )

\subsection{Mistakes Made by the Students Taking Mathematics Graphs}

On the whole, Figure 2 (Appendix B) shows three types of errors made by students. The first error is the concept of straight line similarity, parallel lines have the same gradient, and the $\mathrm{x}$-intercept the y-intercept can be distinguished. Although, PBRL4, PBRL5 and PBRP1 could answer by selecting point Q while problem-solving, the interviews showed that the students did not master these concepts.

'...not a good question... cannot understand...' (PBRP1T1);

'....copy friend' (PBRL5T2)

'... we did not do sir. Don't know where to start...' (PBRP2 \& PBRP5T3)

Subsequent conceptual errors involved PBTP4, PBRL1, PBRL2 and PBRL3. Students knew how to use the concept of gradient but did not solve the problem until they arrived at the answer.

'This one, I don't know... I didn't study when this topic taught because I was busy with sports. Lazy to revise, so difficult...' (PBRL3T5)

The third error was carelessness in determining the $\mathrm{x}$-intercept and y-intercept (PBTL3) and running the algorithms, that is PBTP5, which concurs with the interview:

'change the value 3 to become negative $3 \ldots$ then, it is the right one' (PBTP5T4)

'I make a wrong change...-2 should be 2 . Real silly mistake...' (PBTL3T6)

\subsection{Achievement in Mathematics Problem-Solving}

The mathematical problem-solving test also consisted of five items. Of these five items, items 15 and 14 were the most difficult items. For item 15 , only $32 \%$ of the students answered correctly compared with $68 \%$ of the students who were not able to answer the item correctly. This item also had a low discrimination value of 0.30 . For item 14 , only $45 \%$ of the students managed to answer correctly, compared with $55 \%$ of the students who were not able to answer the item correctly. This item has high discriminatory value compared with item 13 (Table 5).

Table 5. Item difficulty and discrimination for Mathematical Problem- Solving

\begin{tabular}{lccccc}
\hline Item & 11 & 12 & 13 & 14 & $\mathbf{1 5}$ \\
\hline Difficulty index & 0.53 & 0.56 & 0.66 & 0.45 & $\mathbf{0 . 3 2}$ \\
Discrimination index & 0.52 & 0.52 & 0.44 & 0.49 & $\mathbf{0 . 3 0}$ \\
\hline
\end{tabular}

\subsection{Mistakes Made by the Students for Item 15 (Line and Plane in 3 Dimension)}

Based on Figure 3 (Appendix C), respondents generally performed poorly in determining angles. Below are excerpts from the interviews:

'...just do guesswork...' (PBRP1T1)

'Don't know how to answer...Studying time also never enter the head...' (PBRL5T2)

'I didn't do this question, sir...don't know sir...' (PBTP2T6)

The interviews showed that some students used guesswork when they did not know what steps to take. Only PBTL5, PBRL3, PBRP2 and PBRP4 could identify and mark the angle TQS but some could not arrive at a final 
solution. Only PBTL5 arrived at a final solution, but made careless mistakes. The majority of the students, that is, PBTL2, PBTP2, PBTP3, PBTP5, PBRL1, PBRL2 and PBRP1 did not identify the required angle of the line QT and plane PQRS. PBTL2, PBTP3, PBTP5, PBRL1 and PBRL2 did not use the Pythagorean Theorem to get the length of QS and then use trigonometric ratios to find the angle parallel to the results of interviews.

'I just delete here and there. Just find the letter that is in the middle becomes the angle. $\mathrm{T}$ is confirmed because there is no other letter... have to choose $\mathrm{R}$ to $\mathrm{P}$ to $\mathrm{S}$. If it were me, I choose $\mathrm{S}$, then it becomes a $90^{\circ}$ triangle. The calculation for finding the angle, cannot get...' ((PBRP4T7)

\subsection{Overall Types of Errors in Mathematics}

Table 4 shows that $52(57 \%)$ of the 91 students committed conceptual errors. 22 (24\%) students committed careless mistakes while $12(13 \%)$ of the students committed problem-solving errors. Only $5(6 \%)$ students committed value error in mathematics. Overall, students committed all the possible errors under Standard Form (17 errors) and Trigonometry (17 errors). Besides, students frequently committed errors in Linear Equations (12 errors) and Line and Plane in 3 Dimension (11 errors). For conceptual errors, item 15 (Standard Form) was the least understood by students. Conceptual errors include unit conversion from kilometers to meters, standard form and size. 22 careless mistakes were made by students, especially under geometry ( 7 errors). Only 12 students committed problem-solving errors under Linear Equations ( 5 errors). Value errors were the least committed by students (Table 6).

Table 6. Distribution of errors based on mathematics topics

\begin{tabular}{llllllll}
\hline \multirow{2}{*}{ Item } & \multirow{2}{*}{ Title } & \multicolumn{5}{c}{ Type of error } & Total \\
\cline { 3 - 6 } & & & 1 & 2 & 3 & 4 & Errors \\
\hline 1 & Round number & 3 & 2 & - & - & 5 \\
2 & Standard form & 6 & 2 & - & 2 & 10 \\
3 & Angles and parallel lines & 3 & - & 3 & 3 & 9 \\
4 & Polygon & 1 & - & 2 & 1 & 4 \\
7 & Trigonometry & 7 & - & 5 & 7 & 17 \\
10 & Fraction & 3 & - & 3 & 2 & 8 \\
14 & Linear equation & 5 & - & 5 & 2 & 12 \\
15 & Standard Form & 12 & 1 & 1 & 3 & 17 \\
17 & Line \& Plane in 3-Dimension & 7 & - & 3 & 1 & 11 \\
18 & Statistics & 5 & - & - & 1 & 6 \\
\hline Total & & 52 & 5 & 12 & 22 & 91 \\
\hline
\end{tabular}

The major reasons given for errors made were a lack of understanding, procedures being forgotten, a lack of mastery over the concept, negligence in transcribing information from the question, carelessness and guesswork. The reasons for errors made were based on symbols, graphs and problem-solving in mathematics. Reasons cited by students for making errors were the inability to understand, forgetting procedures, and carelessness. Errors in graphs include the inability to understand, lack of mastery of concept and carelessness. Problem-solving errors were caused by carelessness and guesswork. In summary, the errors in mathematics were caused by a lack of understanding, procedures being forgotten, negligence in transcribing information from the question, carelessness and guesswork (Table 7).

Table 7. Reasons for errors made based on symbols, graph and problem-solving in mathematics

\begin{tabular}{llll}
\hline Reasons Given For Errors Made & Symbols & Graph & Problem solving \\
\hline 1.Students do not understand & $/$ & $/$ & \\
2. Procedures being forgot & $/$ & $/$ & \\
3.Did not master the concept & & $/$ & $/$ \\
4.Carelessness / negligence & $/$ & & $/$ \\
5.Guesswork & & \\
\hline
\end{tabular}

\section{Discussion and Implication}

\subsection{Discussion}

The findings showed that symbols were easier for the students when compared to graphs and mathematical problem-solving. This shows that students can understand math better by using symbols. This is in line with 
Suhaidah's (2006) study which showed that symbols are very important to help students to learn the basic mathematic concepts. Although, symbols were relatively easier to solve, students still made errors because they did not understand, forgot the procedures and were careless.

Overall, students faced difficulties in solving the graph items in mathematics. These findings were in line with the study by Ben-Chaim's et al. (2005). According to him, many students have problems in solving graphs. Similarly, Chang (2010) found that students faced difficulties based on nine errors. The errors included slope of a line, incomplete or no response, substitute wrong value, graph value, calculation, not following instructions given/misinterpreting the requirement of the question, identify gradient, addition of negative values indiscriminately, and unacceptable forms. In relation to graphs, this study found three types of errors when solving the graph items. Students did not understand, did not master the concept and were careless. These findings were quite similar to Noor Safiyah's study (2009) which showed that the errors were due to careless mistakes, and erroneous application of mathematical rules.

Based on the analysis of errors, four types of errors have been identified as a whole. The errors included the concept, value, problem-solving and carelessness. The findings showed that the most frequent errors made by students were faulty conceptualization and these findings are consistent with findings by Ben-Chaim et al (2005) Value-based errors were not studied extensively as these errors could be categorized under problem solving, concept and carelessness. Findings by Chang (2010), Noor Safiyah (2009) and Sharmiza (2010) are consistent with the findings of this study which involve problem-solving. Conversely, errors due to carelessness were in line with findings by Noor Safiyah (2009). This finding is also supported by Ruzlan et al. (2013) study on error analysis which showed the lack of conceptual understanding of fractions. Errors occurred because of confusion, insufficient time, anxiety, forgetting the procedures, carelessness, and difficulty of questions.

This study reported a reliability value within a range of 0.74 to 0.86 . for symbols, graphs, problem-solving and mathematics in the analysis of internal consistency. The calculated difficulty index and discrimination coefficient values provide useful input for mathematics teachers to improve their pedagogical practices. The difficulty index is of particular relevance because the more difficult the item, the greater the tendency for the student to commit errors.

\subsection{Implications}

The major reasons given for errors made were a lack of understanding, procedures being forgotten, negligence in transcribing information from the question, carelessness and guesswork. Students are encouraged to consider the suggestions given to improve their transformation of mathematical symbols, graphs and enhance problem-solving. An initial step would be to read the questions carefully and understand the tasks required to avoid misunderstanding of the questions. Additionally, students should avoid copying numbers/information incorrectly and avoid being careless in calculation. Next, students should not neglect basic mathematical skills that involve addition, subtraction, multiplication and division. Mastery of these skills is insufficient if the students are not able to show the mathematical steps in a neat and orderly way in the space provided. Students should also attempt to understand all the topics and not confine themselves to selected topics. Forecasts on potential topics that would be tested might put the student at risk. Finally, students have to write clearly and legibly as students would be at a disadvantage if their written output is incomprehensible.

The reasons students gave for committing the errors provide useful input for mathematics teachers to design teaching and learning activities that help students to be more competent in mathematics. Their comments, narratives and explanations for the errors help teachers to gain useful insights on their cognitive challenges and coherent strategies can be devised to address these challenges. It is important for teachers to be aware of the strategies students take in solving mathematics tasks. Do they have the correct understanding of the basic concepts? Can our student teachers detect the mistakes? The objective of the activity is to help preparing our students teachers to be teachers who are not only looking at the final product of the children's work but as teachers they have to appreciate children's work to follow the process in order to catch' the loophole in the early stage of child learning. The findings suggest that in order to measure students' performance effectively, necessary improvements need to be done where items with poor difficulty and discrimination index should be reviewed.

\subsection{Conclusion}

Generally, most misconceptions in mathematics are a challenge for students. Factors that contribute to misconceptions should also be delicately considered. The study indicates that the difficulty index is particularly useful because the more difficult items pose more challenges for the students, and hence the possibility to commit errors. Thus teachers can take pre-emptive steps to ensure that misconceptions do not arise in the initial 
stages. Teachers should be aware of areas that have the potential to generate misconceptions in the minds of their students. Enough work and examples should be focused on directly addressing the perceived misconceptions. There are many aspects of teaching and student learning that can be evaluated and many strategies employed to help students understand mathematical concepts. This will lead to better learning outcomes and more positive learning experiences, as clarity of concepts increases when misconceptions are reduced. Teachers play a very important role in student learning because when teachers make informed pedagogic decisions, students can be helped to overcome misconceptions.

\section{References}

Ben-Chaim. D., Chang, K. Y., \& Greenes, C. (2005). International Survey of High School Students' Understanding of Key Concepts of Linearity. Israel: University of Haifa; Korea: Konkuk University; United States: Boston University. Unpublished report. Retrieved March 31, 2012, from http://www.emis.de/proceedings/PME31/2/273.pdf

Bond, T. G., \& Fox, C. M. (2001). Applying the Rasch Model: Fundamental, Measurement in the Human Sciences (2nd ed.). London: Lawrence Erlbaum Associates.

Fischben, E., Jehiam, R., \& Cohen, D. (1995). The concept of irrational numbers in higher school students and prospective teachers. Educational Studies in Mathematics, 29(1), 29-44. http://dx.doi.org/10.1007/ BF01273899

Giannakoulias, E., Souyoul, A., \& Zachariades, T. (2007). Students' thinking about fundamental real numbers, properties. Paper presented at the $5^{\text {th }}$ Congress of the European Society for Research in Mathematics Education (CERME5). University of Athens. Greece.

Kailani, \& Natasha. (2011). Penerapan unsur Sejarah Matematik dalam penyelesaian Persamaan Kuad ratik, Punca Kuasa Dua dan Punca Kuasa Tiga (Unpublished Master dissertation). Universiti Teknologi Malaysia, Malaysia.

Kaplan, R. M., \& Saccuzzo, D. P. (2001). Psychological Testing-Principles, Applications, and Issues (5th ed.). Belmont, CA: Wadsworth.

Karim, N. S. A. (2009). Mengkaji jenis kesilapan pelajar dalam soalan berbentuk penyelesaian masalah terhadap topik persamaan garis lurus (Unpublished Tesis). Universiti Pendidikan Sultan Idris. Malaysia.

McNamara, J., \& Shaughnessy, M. M. (2011). Students errors: what can they tell us about what students do understand. Retrieved from http://www.mathsolutions.com/documents/studenterrors_jm_ms_article.pdf.

Ministry of Education. (2001). Perangkaan Pendidikan Malaysia 2001-2010. Kuala Lumpur.

Mullis, I. V. S., Martin, M. O., Foy, P., \& Arora, A. (2012). TIMSS 2011 International Results in Mathematics. Chesnut Hill, MA: TIMSS \& PIRLS International Study Center, Lynch School of Education, Boston College \& Amsterdam.

Ruzlan, M. A., Melvyne, R. R, \& Arsaythamby, V. (2013). Lower secondary school students errors in solving fraction questions. Paper presented at the $5^{\text {th }}$ International Conference on Science and Mathematics Education (CoSMEd 2013) 11-14 November 2013, Penang, Malaysia.

Sabri, S. (2013). Item analysis of student comprehensive test for research in teaching beginner string ensemble using Model based teaching among music students in public Universities. International Journal of Education and Research, 1(12), 1-14.

Schuhmann, P. W., McGoldrick, K. M., \& Burrus, R. T. (2005). Student Quantitative Literacy: Importance, Measurement, and Correlation with Economic Literacy. The American Economist, 49(1), 49-66. Retrieved from http://www.jstor.org/stable/25604313

Shamsuri, S. (2010). Analisis kesalahan pemahaman konsep dalam matapelajaran matematik dan punca-puncanya dalam topik statistik (melakar ogif) (Unpublished dissertation). Universiti Pendidikan Sultan Idris. Malaysia.

Sirotic, N., \& Zazkis, R. (2006). Making sense of irrational numbers; Focusing on the representation. In M. Johnson-Hoires, \& A. B. Fuglestad (Eds.), Proceeding of the 28th Conference of the International Group for the Psychology of Mathematics Education (pp. 497-504).

Tahir, S. (2006). Pemahaman Konsep Pecahan dalam Kalangan Tiga Kelompok Pelajar Secara Keratan Lintang (Unpublished PhD dissertation). Universiti Teknologi Malaysia.Malaysia. 
Tuba-Ada, \& Aytac-Kartulus (2010). Students' misconception and errors in transformation geometry. International Journal of mathematical Education in Science and Technology, 41(7), 901-909. http://dx.doi.org/10.1080/0020739X.2010.486451

van Es, E. A., \& Judi, C. (2009). Using the Performance Assessment for California Teachers to Examine Pre-Service Teachers' Conceptions of Teaching Mathematics for Understanding, Issues in Teacher Education, 18(1).83-102.

Yoke, C. M. (2010). Jenis-jenis kesilapan dan punca-puncanya yang biasa dihadapi oleh pelajar tingkatan 4 dalam kecerunan garis lurus (Unpublished Master dissertation). Universiti Pendidikan Sultan Idris, Malaysia.

\section{Appendix A}

\section{Item $\mathbf{4}$ is the most difficult in symbol achievement.}

A rectangular piece of land measures $6.5 \mathrm{~km}$ long and $3.4 \mathrm{~km}$ wide. Find the area of the land, in $\mathrm{m}^{2}$. Express your answer in standard form.
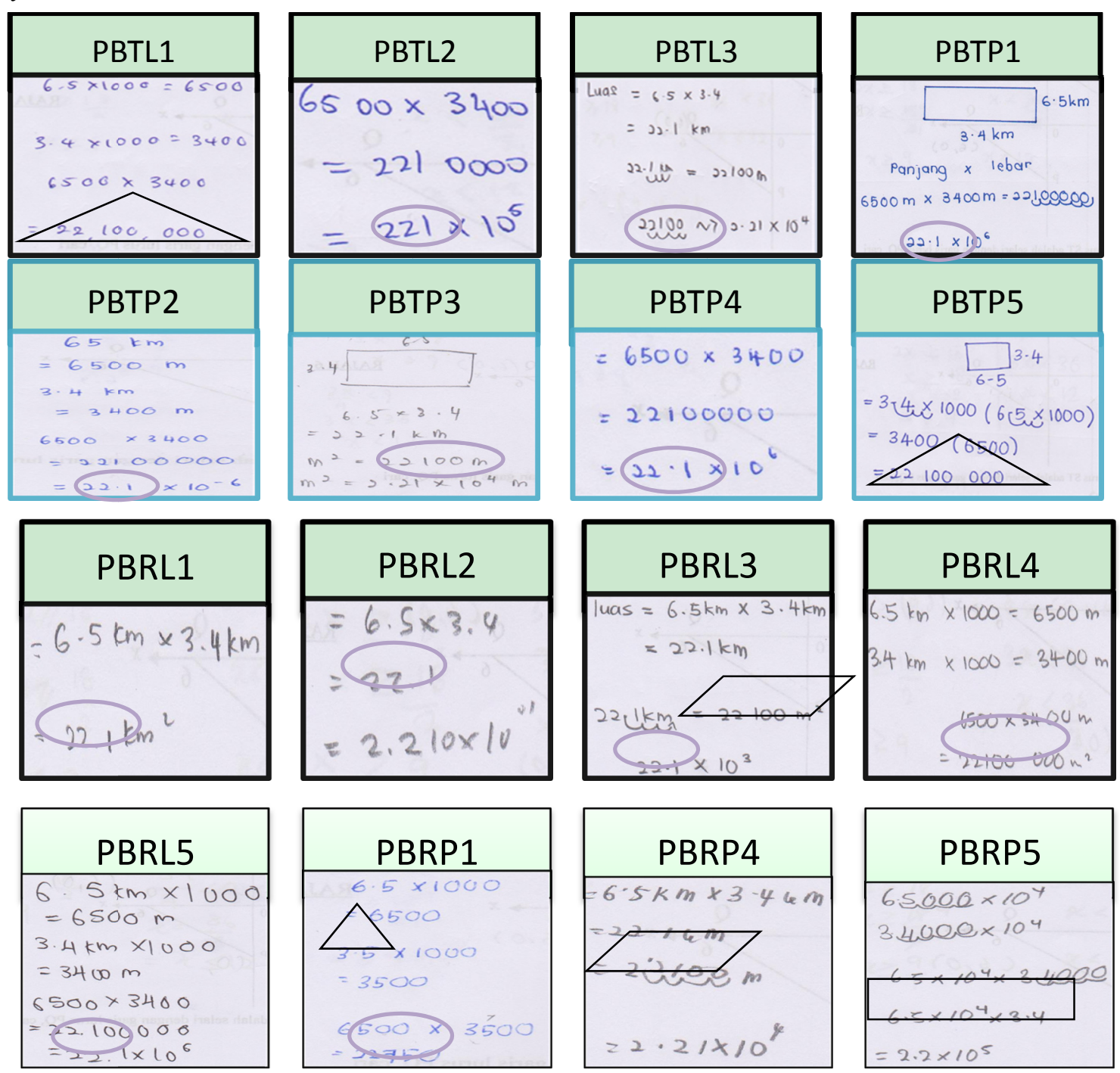

Figure 1. Error analysis for item 4 (Standard Form)

\section{Appendix B}

Item 6 (linear equation- difficulty index is 0.29 )

In Diagram 1, the straight line ST is parallel with the straight line PQ. Find the equation of the straight line, PQ. 


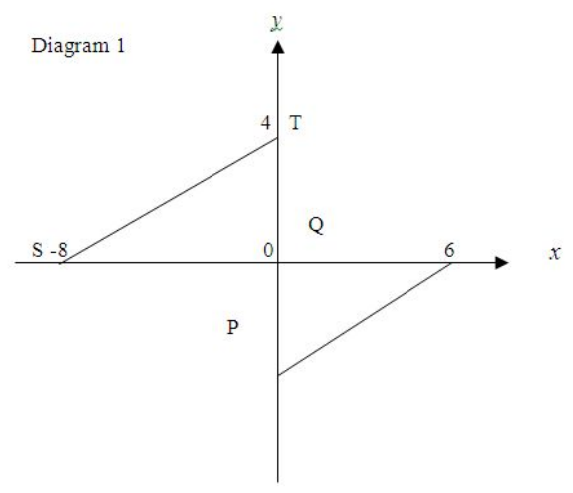

Mistakes made by the students taking mathematics graphs
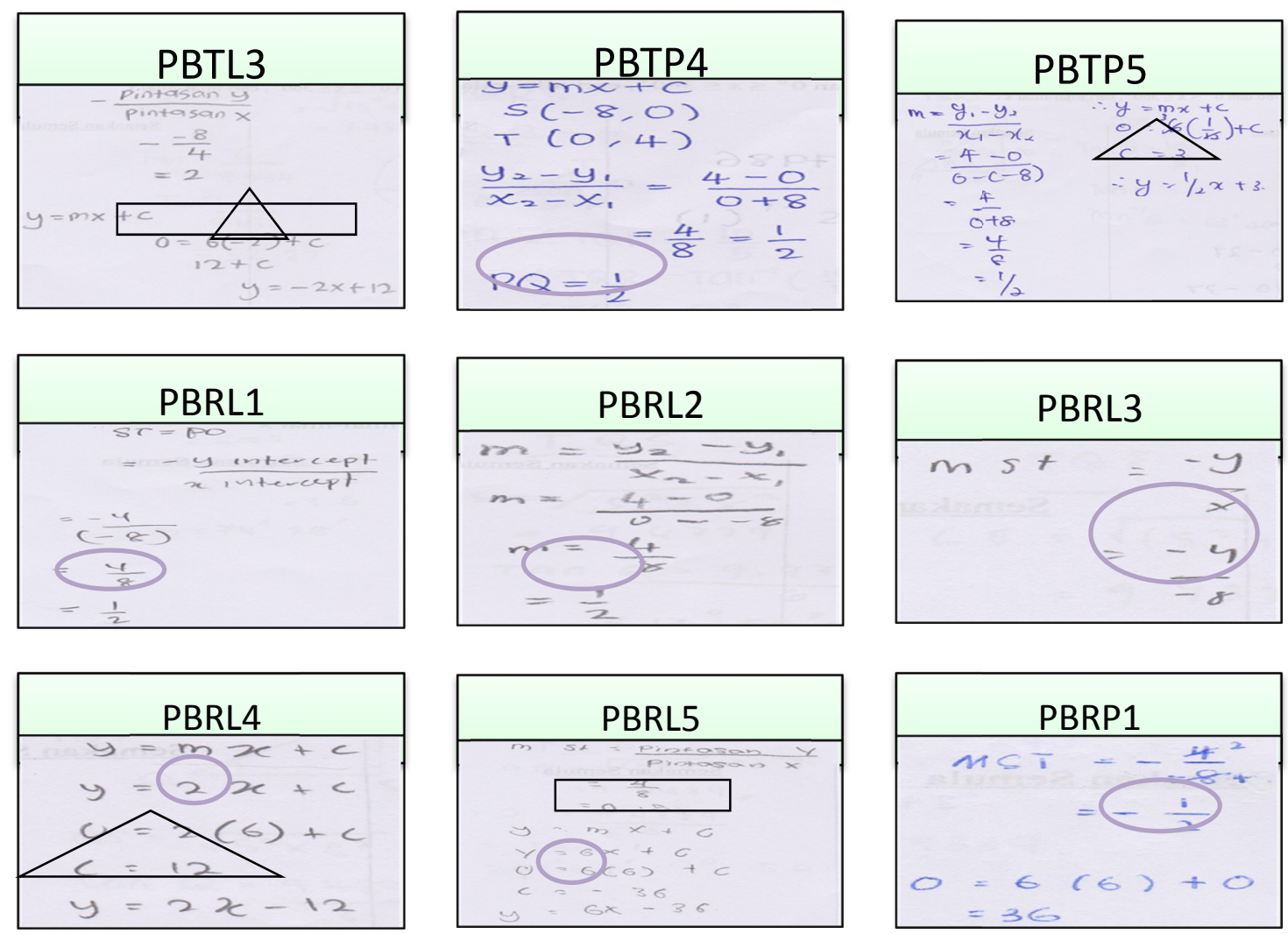

Figure 2. Analysis of error in Question 6 (Linear Equation)

\section{Appendix C}

Item 15 (Line and Plane in 3 Dimension)

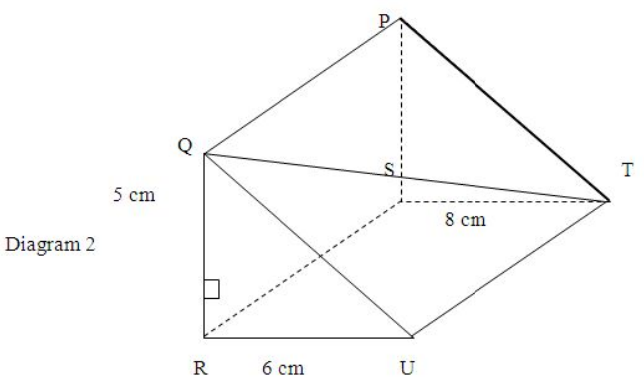


Figure 3 shows a prism having a horizontal rectangular base RSTU. Calculate the angle between the line QT and the plane PQRS.
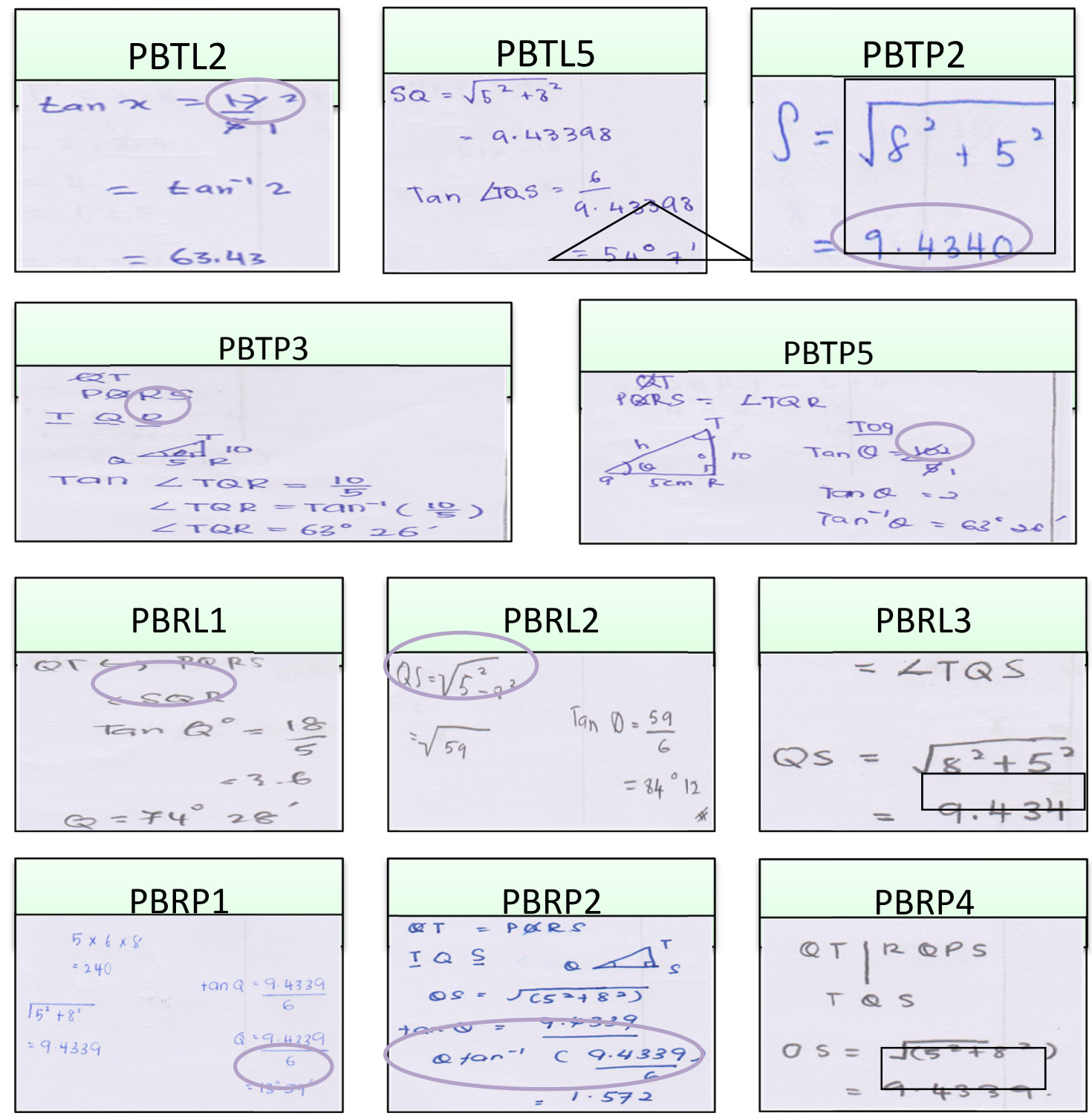

Figure 3. Error Analysis for item 15 (Line and Plane in 3 Dimension)

\section{Copyrights}

Copyright for this article is retained by the author(s), with first publication rights granted to the journal.

This is an open-access article distributed under the terms and conditions of the Creative Commons Attribution license (http://creativecommons.org/licenses/by/3.0/). 